Island Studies Journal, Vol. 8, No. 1, 2013, pp. 55-66

\title{
Reading the Planetary Archipelago of the Torres Strait
}

\author{
Elizabeth McMahon \\ University of New South Wales \\ Sydney, Australia \\ e.mcmahon@unsw.edu.au
}

\begin{abstract}
This essay makes use of the Western concept of the archipelago as a starting point for an examination of island to island relations in the Torres Strait, Australia, as they are rehearsed in the imaginary domain of story, in both its written and oral modes. The essay deploys Spivak's notions of planetarity and Bloch's concept of utopianism as ways of charting the relationship between two Torres Strait stories, one old, one new. In so doing, the essay seeks to identify the capacity of Torres Strait literature and storytelling to re-conceive relations of space and time and to acknowledge a spatial and temporal mobility running parallel to the circumscribed trajectories of late modernity.
\end{abstract}

Keywords: archipelagos; Gayatri Spivak; globe; islands; novels; planetarity; story-telling; Torres Strait

(C) 2013 Institute of Island Studies, University of Prince Edward Island, Canada.

\section{Introduction}

This essay deploys the Western concept of the archipelago as a starting point for an examination of island to island relations in the Torres Strait, between the north-east of continental Australia and Papua New Guinea, as they are rehearsed in the imaginary domain of story in both its written and oral modes. The approach taken is informed by Gayatri Spivak's keynote address at the 2012 conference of the Association of American Geographers (AAG) in New York City, which underscored the many connections between her conception of planetarity and the various projects of geographical studies. Spivak's spatial understanding will be augmented by its consideration alongside literature's capacity to confound temporal categorization, as theorized by Ernst Bloch and Édouard Glissant. In this way, the discussion seeks to identify the capacity of literature and storytelling to re-conceive relations of space and time, and to acknowledge a spatial and temporal mobility running parallel to the circumscribed trajectories of late modernity.

Of particular relevance to a study of islands is Spivak's distinction, though not opposition, between the globe and the planet. At the AAG, Spivak (2003, p. 72) reiterated her critique of capitalism's global geography, and her call for 'the planet to overwrite the globe'. She wrote that the "globe is on our computers. It is the logo of the World Bank. No one lives there" and we think we can control it. The "planet' is "in the species of alterity", yet we "inhabit it, indeed are it" (ibid., p. 338). Others have made similar claims, most significantly perhaps Paul Virilio (1993) in terms of his thesis on the end of geography in globalization, and Frederic Jameson in his numerous critiques of globalization (1998; 2000). However Spivak's formulation has particular resonance for the current discussion for its juxtaposition of the conceptual spheres of the island earth. In Spivak's distinction, the globe is a totalizing image of 
reified ideology while the planet holds the vital contradiction that lived experience only ever offers partial perspectives and understandings which are admittedly imbricated in the flow between material and fantasmatic space.

Islands have a specific pertinence to the global habit of thought and its re-imagining in planetary terms, for they are so often conceived as miniature worlds and as objects of mastery. Conventionally, this epitomic function may invert so that the miniature contains the enormous: As Kenichi Ohmae prophesied (1990, pp. x-xi) in A Borderless World:

An isle is emerging that is bigger than a continent - the Interlinked Economy of the Triad (the United States, Europe and Japan) joined by aggressive economies such as Taiwan, Hong Kong, Singapore ... It is becoming so powerful that is has swallowed most consumers and corporations, made traditional national borders almost disappear.

Today's reader will be struck by the shifts in power from 1990 to 2013, providing a critique of endgame capitalism in itself. However, Ohmae's use of the world island here follows the convention of the island as a homogenous space, disavowing difference, a figure that Connery (2001, p. 174) elsewhere refers to as an effect of capitalism's "disintermediation" of space. A planetary consideration of islands, then, insists on the internal intermediations of islands and the archipelagic model may further identify their complex and overlapping intermediations between islands and between land and sea.

The archipelagic model may achieve this perspectival shift for its capacity to conceptualize "a world in process"-Deleuze's (1997, p. 86) utopian description-by which it may destabilize what Beer (1990, p. 271) describes as the "particular and intense relationship of land and water" implicit in the Western concept of individual islands (also Edmond \& Smith 2003 , p. 9). This binarism has been roundly critiqued in Island Studies, most profoundly by Epeli Hau'ofa's description of the Pacific as a sea of islands (Hau'ofa, 1993; also DeLoughrey, 2001). In the specific context of the current discussion, one of the chief limitations imposed by the land/sea binary is that it defines islands according to a relation of fixed intransigence which, in turn, excludes them from the diverse mobilities of late modernity in ways real and imaginary. An archipelagic perspective may provide a counter to the imagined fixity of islands by its supposition of their multiplicity and mobility, thereby challenging the hierarchical relations between continent and islands. In terms of scholarly perspective, an archipelagic frame may be able to dislocate the privilege of the viewer/scholar so that their relationship with islands and islanders is between 'planetary subjects' rather than of 'global agents'. This re-formed relation includes a new dynamics that destabilizes the imagined fixity of panoramic authority to show its multiple contingencies, and accords mobility to island and islanders in an admission that they will always escape comprehension by dint of complexity, difference, and relentless processes of change.

Torres Strait Islander academic Martin Nakata (2007, p. 2) records his sense of alienation from the "cross-cultural and Indigenous Australian components" of his university study in terms of this fixity. He writes:

It was as if Indigenous people were an object of study viewed from the confines of a fixed vantage point. Our perspective - the Islanders' point of view-was mostly obscured from view and, it would seem, irrelevant as it could always be explained away by theoretical knowledge. 
In this instance, the 'fixed vantage point' of disciplinary knowledges is exposed as being more blind than illustrative. Further, islanders may be doubly-erased in this process because islands are over-determined objects of knowledge for the Western eye. Their appeal as ideal laboratories with fixed borders is attended by heavily-scripted economies of observation and data collection, in which islands are models of the world schematic 'captured' in microcosm and in time. What is needed in this scholarly process, then - particularly one that negotiates a complex grid of difference - is a readiness for continuous displacement. For, as planetary subjects rather than global agents, "alterity remains underived from us"; it remains separate from our projections and investments. Accordingly, it "contains us as much as it flings us away" for we do not control it (Spivak, 2003, p. 73).

In the 2011 collaborative essay Envisioning the Archipelago, Stratford et al. (2011) echo Spivak's call to scholars to become engineers of displacement. They identify the archipelago's capacity to effect this kind of dislocation in the reality and metaphorics of islands, for their multiplicity and inter-relations confound the fetishizing gaze upon a single island and require viewers to be, themselves, 'at sea'. As such, the project is, in part at least, formally utopian, a formulation of especial relevance given the role of islands in utopian thought. However, it also brandishes a checklist of correctives against generalist utopian impulses. Specifically, the archipelago's capacity to unsettle island boundaries and to identify island mobility needs to be read against the uncritical embrace of the 'boundarylessness' of global cosmopolitanism, as discussed above.

These various understandings of island mobility, inter-relation and contradiction may not be new to islanders themselves; but their identification here intends to underscore the multiple understandings of island to island relations and to suggest their proliferation and interaction. This promise of variation is illustrated by the diverse formulations proposed by island writer-theorists - what DeLoughrey (2001) terms archipelagraphies. These include, iconically, Tongan Epeli Hau'ofa's (1993) description of Oceania as a sea of islands, Barbadian Edward Kamau Brathwaite's (1983) theories of tidalectics, St Lucian Derek Walcott's (1990) interweaving of the material and figurative archipelagos of the Caribbean, Cuban Antonio Benítez Rojo's (1996) formulation, from Chaos theory, of the repeating island; and Martinician Édouard Glissant's (1997) understanding of the interconnected relation of islands as a model, not only for the Caribbean archipelago, but for monolithic continents.

These writer-theorists speak from within the material and imaginary lives of their archipelagos, and are consequently divergent and inventive. Significantly, such richness and variation suggests that there exist many more understandings of island to island relations, of intrinsic value and interest, which may be similarly powerful in re-directing thinking about islands at this time. ${ }^{1}$ Moreover, the list of the poet-theorists above suggests multiple reasons why it may be productive to look for these formulations in the articulated poetics of place. For their poetics of place may imagize and articulate unconscious operations of collective affect and meaning; which is to say that the formal properties of the works (narrative, tone, plot, focalization, figuration) may retain both the charge and intensity of their original production and the dilemmas and questions they address. So, too, in that such writings and transliterations may contain depictions of life and experience, they are sources of cultural information

\footnotetext{
${ }^{1}$ Juni'Chiro Suwa's (2007) discussions of the Japanese concept of shima (島) the island as geography and as a densely populated area, draws the inter-connections between natural and cultural constructions of islands, a complexity to which the island cultures journal Shima directly alludes.
} 
including, inter alia, the relationship between material and symbolic forces. So, too, the particular circulations of stories within and across island groups may signify patterns of cultural connection.

\section{'Stories under Tagai' project}

All of these operations were in evidence in 'Stories under Tagai', a traditional story-telling project that formed part of the Torres Strait Cultural Festival in November 2012. Terena Hopkins, Regional Director of the Queensland State Library, described the initiative as taking numerous forms: "Generally an elder would sit with the children and tell a story, other times they would be retold through dance" (Davis, 2012, np). The high level of interest in the process meant that recordings of the events, originally intended only for those communities directly involved, became incorporated into the festival so that people from the outer islands could also participate and celebrate the process. The relevance of the stories extends across and beyond the Torres Strait, as Mabuiag Island elder, John Whop, makes clear: "These are Australian stories. This is part of Australian heritage and these kind of stories must become part of Australian folklore" (ibid.). In considering these multiple operations and circulations, the mode of reading Torres Strait island narratives I am suggesting includes the conventional practice of detailed attention to textual operations (a vertical process), and one that is more horizontal or cultural and which attends to the circulation of texts and their social effects.

Informing all aspects of this reading practice is the utopian formulation that interconnects temporalities, extending Spivak's planetary formulation. In his recent rendering of the 'transnation', postcolonial theorist Bill Ashcroft (2011, p. 21) re-emphasizes the ways literature operates as a site of utopian possibility because of its capacity to imagize other worlds, other futures. Glissant (1989, p. 64) refers to this capacity as affording a "prophetic vision of the past" while utopianist Ernst Bloch (1986, p. 45; 1988, p. 41) describes it as enabling “anticipatory illuminations". Glissant's 'vision' and Bloch's 'illuminations' overturn the sequence of past, present and future, allowing access to cultural memory and the representation of the future outside the prescriptions of national history. In this way Glissant offers a means to access unrecorded and forbidden histories and to recontextualize the experience of colonial imposition as other than definitive for the present and the future. In its aim of over-riding the limitations of official accounts, Glissant's (1988, p. 6) formulation resonates with Bloch's understanding of literature's capacity to represent the "not-yetconscious" and hence foreshadow humanity come to itself.

Bloch's (1988, p. 8) foundational conception of futural 'hope' rejects the Platonic idea of anamnesis (knowledge as re-remembering) which, Bloch asserts, aligns 'Beingness' with 'Been-ness' in its deflection from the future. As John Whop recognizes in relation to the 'Stories under Tagai' project, "re-telling old tales gives them new life", the stories are not archives of the past but pertain to the present and future (Davis, 2012, np). The utopian vision does not relegate the past to a delineated category or commodity, but instead renders the future visible in the past, as "avenged and inherited, mediated and fulfilled" (Bloch, 1986, p. 9).

In discussing 'Bloch and Tradition', Bloch's English translators summarize his argument in terms of cultural 'surplus': "from all progressive thinking, a utopian surplus carries into the future. Its significance may lie dormant before new social conditions recall it and extract its new meaning" (Plaice, Place \& Knight in Bloch, 1986, p. xxvii). Thus, Bloch's rethinking of the temporal relations and the desired collapse of temporal categories is 
determinedly not ahistorical. On the contrary, it rejects the regressive movement back to prehistory and animates the generative potential of cultures across time, as understood by the 'Stories under Tagai' project. The utopian approach thus constructs a framework for reading the stories of the Torres Strait in their mutual inter-relation across time, to identify the 'surplus' that may speak to present and current uncertainties about the future. Specifically, we will read a traditional story from Moa Island of the Near Western group in the Torres Strait archipelago in view of issues of moment that shape the present and future: land-water relations, claims to ownership, and creativity. This story will then be placed alongside a 2005 novel of Thursday Island of the Inner Islands group. The dialogue between these two texts, I suggest, confounds temporalities so that the more recent narrative animates the older story as it is simultaneously animated by it.

In his essay on Torres Strait islanders' management of the marine environment, Canadian anthropologist Colin H. Scott (2004) makes several observations regarding the islanders' relationship between land and water. He quotes one traditional owner, who spoke to him during his time on the islands, as saying: "our feet are on the ground, but our hands are in the sea" (ibid., p. 259) Land and sea are linked by the human body. The sea as much as the land is a cultural site of homeplace, ownership and control. This understanding is supported by Nonie Sharp (1993, p. 49; 2002, p. 31), who has conducted a great deal of research in the Torres Strait. She writes of the Meriam or eastern islands:

Location is primary ... every person (including an unborn child) must have a ged or homeland. In social life these homelands are situated along the sandbeaches fronting the sea and the horizons. Relationship to place creates a simultaneous relationship to ownership of portions of foreshore, reefs, cays, and outer seas, including fishing grounds, the wind which blows on that particular quarter, particular stars in their rising or waning phases and given structures of clan and kin, relationship to place is integral to social relationships with other groups (Sharp, 1996, p. 84).

\section{My Island Home}

These views of place and homeplace sound both similar and utterly foreign to the Western binary of land and sea and of the island as object of ownership. The imagined connection between these different conceptualizations was played out when Christine Anu, whose family comes from Mabuiag and Sabai islands in the western Torres Strait, performed 'My Island Home' at the closing ceremony of the 2000 Sydney Olympics (McMahon, 2003), as a kind of Australian signature. The song, written in 1985 by Neil Murray for his fellow Warumpi Band member George Burarrwanga, originally referred to Burarrwanga's home, Elcho Island in Arnhem Land in Australia's Northern Territory (Connell, 1999). Murray and Anu adapted the song and Anu recorded it in 1995. It won 'Song of the Year' at the 1995 Australasian Performing Rights Association (APRA) awards, which also listed it as one of the "top thirty Australian songs of all time" in 2001-Anu being one of only two women performers listed in any capacity (APRA). The song catapulted Anu to fame and became a kind of unofficial national anthem. 
Thus the song already referred to multiple island homes before the 2000 Sydney Olympics. On that global occasion, Australians related to the song in reference to their island continent, and connected with the international audience so that all were united on the island of the earth. The progression of amplification in this range of island identifications, from a single small island in Arnhem Land or the Torres Strait to the globe, operates conventionally as a Platonic correspondence from island microcosm to planetary macrocosm. And yet, each of these island homes does not fold seamlessly into the other as they open out into a global scale. While each invokes concepts of home, ownership and identity, these concepts are understood differently and carry different degrees of access and rights of possession. The moment of unified anchorage enabled by 'My Island Home', while meaningful, also produces a 'disintermediation' of space, a globalized homogeneity where the only distinction is scale.

\section{Wami's Banana Tree}

The Myths and Legends of the Torres Strait-compiled and translated by Margaret Lawrie (1970) at the behest of Torres Strait Islanders, and included in UNESCO's Australian Memory of the World Register - presents a complex range of stories, many of which chart land-sea trajectories of ownership. One story which exemplifies the specificity of these understandings is Wamin Ngurbum (Wami's Banana Tree), told to Lawrie by Wees Nawia at Kubin, Moa Island (also Mua), in November 1967. Wees Nawai was an elder of that community and led it in a move from Poid to Kubin on Moa island in the inter-island migrations after World War II.

In this story, a man named Wami, for many years a madub - an idle, lazy or apathetic man, characterized by a lack of success in planting - one day espies an object in the waves of the sea (Lawrie, 1970, p. 61). It is a banana sucker. He takes it and addresses it: "You are Wami's banana sucker." He croons to it; indeed it is a form of love object: "My beautiful banana sucker. I am going to dig a fine hole in the ground for you" (ibid., p. 33). He is faithful in his attention and gazes upon it all day. As the tree emerges, Wami invents a song of ownership, which he repeatedly sings, thereby attracting the attention of the other villagers:

\section{Madubul ina kuruai iudanu}

Bgai (gar) Wami (a) Wami.

(This curving stem weighed down with ripening bananas belongs to the madub.

I am Wami, Wami. It is mine) (ibid., p. 34).

The villagers request suckers from the tree but he refuses. Eventually he says:

When the bananas are ripe, I shall cut off the bunch. After that I will give a sucker to the village people. But remember this: everyone is to call it by my name. This banana is Wamin ngurbin (ibid., p. 34).

The storyteller, Wees Nawia, adds to this story proper that Wami kept his word and that the madub was the first kind of banana grown on Mua. 
The story maps the interconnected concepts of ownership, land and sea. Firstly, the ownership of the banana sucker is individual. It is an originary material, an original plant, but this material object already contains the immaterial, the force or spirit of itself and its charge of meaning. It is, as such, both object and force. This force is concurrently natural and beyond the natural, as marked by its discovery in the sea, which is not the natural place for such a plant, and by its supernatural appearance. Its transplantation, like the relocation of a found object in modern art practice, intensifies the power of this object/force well beyond its utility. This excess or surplus is further enhanced by the alchemic intensity of Wami's relationship to the plant; indeed, by the love that is generated.

The transplanting of the banana sucker from the sea to the land, effects the transformation of Wami from a madub, so that he becomes the owner of the most coveted plant, and is transformed into a proud cultivator and negotiates with the broader community. The force of both the plant and its relationship with Wami recreates the man who thus becomes legendary in this culture of great cultivators. It is he (with his feet on the land and his hands in the sea) who is the human agent of this magical productivity and creativity. This intervention is one of love.

Significantly, Wami will only share this plant once it has borne fruit. For then it is truly his and the originary status of his tree is established. Only then will he share the tree with others. This distribution does not occur within the limit of the story but remains a promise, folding into the future. This future is realized in the story-teller's postscript, which assures the listener that Wamu kept his promise and the banana becomes a shared and enduring plan of the island and of community. However this temporal dialogue does not foreclose the future of the time of story-teller. Rather, it leads us back into the surplus or hope of the story itself and its enduring capacity for generation, for the creation of the future itself.

\section{Butterfly Song}

We find a similar, if modernized, version of this economy in the novel Butterfly Song by Terri Janke, of Thursday Island. Janke's family moved from the island to Cairns after the Second World War, at the same time that Wees Nawia led his community in their move from Poid island to Moa. Butterfly Song opens:

They say if you live on an island for too long, you merge with it. Your bones become the sands, your blood the ocean. Your flesh is the fertile ground. Your heart becomes the stories, dances, songs. The island is part of your makeup. The earth. The trees. The reef. The fish. The music. The sun, moon and stars surround you. You are only part of the integral world called life. You and those who follow you will always be a part of it. No matter where you and your children will travel, the island is always home (Janke, 2005, p. $1)$. 
The novel's overture establishes the interconnectedness of the human with the island home: its land and water, its life forms, its human culture. It differs markedly from the Western figure of the island as an epitome of the human or the globe, expanding or contracting along a scale of correspondences, only differing by size rather than by a complex of elemental differences. What is also claimed at the outset is a form of ownership based on interconnection within this grid and its related conception of home, even when the subject is physically absent. This form of island inhabitation is in direct contrast to the 'globe', the place where no one lives, in Spivak's description; it is inherently planetary, for people "inhabit it, indeed are it".

The temporalities of "too long" and "always" in this opening claim suggest eternal or monumental time, especially as these confound the imperatives of historical time with its fixed linear perspective and its record of events. But the ensuing narrative inserts history into this eternal temporality, weaving both the parallels and the interplay between them. Part of the effect of these overlaid places and times, I suggest, is the identification and continuance of the same kind of 'surplus' at work in Wami Ngurbum. In making this comparison, the discussion traverses the genre of myth to that of a realist novel in which shared concepts, images and desires of the earlier text are transposed into novelistic form. Specifically, in this process the compounded symbolism of myth becomes dispersed across the extended narrative of Butterfly Song. So, too, characters are located in space and time and accorded interior lives, unlike Wami who is accepted as a madub and whose interior motivations are never explained. However, these very transpositions underscore the connections and the generative surplus at work for we can identify similar capacities for generation, for the creation of the future at a time when island futures are very uncertain.

The narrative of Butterfly Song traces the experience of Tarena, living in Sydney and completing a law degree, who is called back to Cairns, on the north east coast of the mainland, and then to Thursday Island. Her mother and uncle have a double-sided request: they ask Tarena to attend a family funeral and to assist them with the reclamation of a family heirloom, a pearl shell with a part-formed pearl creating a small, rounded dome. The shell was carved and shaped into a butterfly by Tarena's grandfather for her grandmother but 'collected' (stolen) by a doctor who attended her grandmother in her final days. The butterfly has now re-appeared for sale for a sizeable sum. The novel stages a series of incidents and encounters though which Tarena reconnects to Thursday Island as her past, present and future homeplace wherever else she may be and whatever other homes she may create. This claim is the motivation and core of this novel. The opening statement that "[n]o matter where you and your children will travel, the island is always home" is unpacked, rehearsed, and animated by narrative events. It is a textual act in the original meaning of text (to weave), in that narrative and events weave the threads of ongoing connection to homeplace.

The novel is, as such, a tale of ownership, about right of possession, and the components of Tarena's experience circulate between her reclamation of the sense of the island as home according to the cosmology of the novel's opening description and the rightful repossession of the butterfly. Tellingly, the eventual proof of ownership, the mark of its originary creation, is a tiny engraved guitar signature of the maker. The intersecting narratives of ownership and belonging, in this case a repossession of an object of great force, an object carved out of love, and the reclamation of familial connection from an earlier estrangement, map the complexity of specific rights, collective identity and place. 
Butterfly Song, like Wami Ngurbum, charts a movement of an object from its unnatural placement - in this case it is in the wrong hands - to its right and proper place. In the novel, too, the object emerges first from the sea, is transformed by human artistry, just like Wami's banana sucker, and becomes the talisman of creative connection between two people. It is only restored to its proper place when family is also restored, and this occurs through the knowledge and experience of place. So, too, the object's theft and commodification was a travesty of the system of exchange by which the object has meaning. Its restoration re-establishes circulations between community; it becomes again a living object. In Spivak's terms, it is not longer rendered static in the reifying economy of the globe but set in motion within planetary relations of lived experience.

Tarena appears to be the antithesis of the lazy, idle figure of Wami, in her ready undertaking of study and work. But, like Wami, Tarena begins this narrative outside her community and is struggling to find her place in the world. Her transformation over the course of the novel performs her re-integration to family and homeplace which, in turn, effects an integration of her identity. Accordingly, the novel shows that the integration of self and world is effected by her role and place in the restitution of the family talisman, and her openness to its generative intensity.

The intense romance of Wami and the object/artefact in the earlier story, which effects his transformation and integration, becomes dispersed in Butterfly Song, as one would expect in a novel, across the numerous meanings of the butterfly brooch itself, including the love of the grandparents, and Tarena's own romance with the musician Sam. Erotic romance and experience in Butterfly Song does not conform to the romance convention whereby the alignment of love and sex acts as a form of narrative resolution and closure. In Butterfly Song, the erotic charge and sexual experience signify the surplus that confounds temporal divisions. In temporal terms, Sam and Tarena's union is a fulfilment of the past, now "avenged and inherited, mediated and fulfilled" (Bloch, 1986, p. 9). But the charge of excess is also futural just as Wami's promise to the villagers projects to the time of fruition. In Butterfly Song the relationship is left unresolved, each party pursuing earlier plans, and we are left looking forward to when their encounter may be reframed and re-made. So, too, this potential, while open-ended, is also intimately connected to place: Thursday Island. In this way the sex between Tarena and Sam operates within the same cosmology as that which opens the novel and which folds them into the island itself: "Your bones become the sands, your blood the ocean. Your flesh is the fertile ground" (Janke, 2005, p. 1). This intimate intensity is not presented as a binding or even enduring encounter but is part of the charge of the place, and the process of reconnection, at the same time as it recharges this place and creates its futurity.

\section{Conclusion}

These stories chart precise boundaries and territories, and record the processes and legacies of living in intermediated spaces in which human animation and energy constantly encounter transformative and generative forces beyond the borders of a single identity. Such encounters of intensity carry forms of surplus, those elements of creative excess beyond the circumstantial constraints of history, that enable imagined possibilities to surpass the constraints of any one temporal category. They represent, in Deleuze's (1997, p. 86) description of the archipelago, a "world in process" wherein the past mutates into the present and future in ongoing assemblages. The highly specific terms of ownership rehearsed and negotiated in these encounters also 
confound divisions of land and sea, which are understood to be in dynamic flux. Human communities and individual experiences occur within these rhythms, in ways akin to Brathwaite's cyclical understanding of tidalectics; but, in the Torres Strait Stories examined here, the acknowledgement of cyclical time must sit alongside the unfolding of futurity.

In all these profound ways, the 'world[s] in process' captured and imagined in the stories discussed in this essay confound the global perspective of mastery and reification to create what Spivak terms planetary relations. This creative surplus will not magically resolve the problems of the future, or indeed the present, but it clearly indicates that alternative geographies of hope are possible, indeed are already imagined. In the case of the Torres Strait narratives, we can glimpse a profound and recurring image of inhabitation as synonymous with the elements of the planet itself. The stories offer a parallel vision alongside global mobility and the reified stasis of mastery. For in the place of stasis they offer an endurance, a model of ownership that is sustained across time and distance, and which is continuously revived. And in the place of the global mobility of capital, they offer an archipelagic capacity to sustain connection and meaning across land and water.

John Whop called for Torres Strait stories to be acknowledged as Australian stories, to be "part of Australian heritage" (Davis, 2012, np). That is long overdue. They might also provide significant ways of re-imaging relations though and across land and water for the planet at a time when we need such notions so urgently.

\section{Acknowledgements}

An earlier version of this paper was delivered as part of a full day of papers on Islands at the annual conference of the American Association of Geographers, New York, 2012. Attendance at the conference was funded by a Discovery Project titled 'Our Island Home' funded by the Australian Research Council. The ideas behind this paper have benefited also from collaborative work undertaken with Elaine Stratford.

\section{References}

APRA (2013). APRA Top 30 Australian songs, Wikipedia. 20 January 2013. Retrieved from http://en.wikipedia.org/wiki/APRA_Top_30_Australian_songs

Ashcroft, W. (2011). Australian transnation. Southerly, 71(1), 18-40.

Beer, G. (1990). The island and the aeroplane: the case of Virginia Woolf. In H. Bhabha (ed.) Nation and narration (pp. 265-290). London: Routledge.

Benítez-Rojo, A. (1996). The repeating island: the Caribbean and the postmodern perspective. Durham, NC: Duke University Press.

Bloch, E. (1986). The principle of hope. Trans. N. Plaice, S. Plaice \& P. Knight. Cambridge, MA: MIT Press.

Bloch, E. (1988). The utopian function of art and literature. Trans. J. Zipes \& F. Meckleburg. Cambridge, MA: MIT Press.

Brathwaite, E.K. (1983). Caribbean culture: two paradigms. In J. Martini (ed.) Missile and capsule (pp. 9-54). Bremen, Germany: Universitat Bremen. 
Connell, R. (1999). My island home: the politics and poetics of the Torres Strait. In R. King \& J. Connell (eds.) Small worlds, global lives: islands and migration (pp. 195-212). London: Cassell.

Connery, C.L. (1996). The oceanic feeling and the regional imaginary. In R. Wilson \& W. Dissanayake (eds.) Global local: cultural production and the transnational imaginary (pp. 284-311). Durham, NC: Duke University Press.

Connery, C.L. (2001). Ideologies of land and sea: Alfred Thayer Mahan, Carl Schmitt, and the shaping of global myth elements. boundary 2, 28(2), 173-201.

Davis, S. (2012). Torres Strait Festival celebrates 'Stories under Tagai', 18 September, 10:21AM AEST, ABC Far North Queensland, 21 November 2012, Retrieved from http://www.abc.net.au/local/stories/2012/09/18/3592396.htm

Deleuze, G. (1997). Bartleby; or, The Formula. In Essays Critical and Clinical (pp. 68-90). Trans. D. Smith \& M. Greco. Minneapolis, MN: Minnesota University Press.

DeLoughrey, E. (2001). 'The litany of islands, The rosary of archipelagoes': Caribbean and Pacific archipelagraphy. ARIEL: A Review of International English Literature, 32(1), 21-51.

Edmond, R, \& V. Smith (eds.) (2003). Islands in history and representation. London: Routledge.

Glissant, É. (1989). Caribbean discourse: selected essays. Trans. with Intro. by J.M. Dash. Charlottesville, VA: University Press of Virginia.

Hau'ofa, E. (1993). Our sea of islands. In Waddell, E., Naidu, V. \& Hau'ofa, E. (eds.) A new oceania: rediscovering our sea of islands (pp. 2-16). Suva, Fiji: University of the South Pacific.

Jameson, F. (2000). Globalization and political strategy, New Left Review, 4, 49-68.

Jameson, F. (1998). Notes on globalization as a philosophical issue. In F. Jameson \& M. Miyoshi (eds.) The cultures of globalization (pp. 54-80). Durham, NC: Duke University Press.

Janke, T. (2005). Butterfly song. Ringwood: Penguin.

Lawrie, M.L. (1970). Myths and legends of Torres Strait, St Lucia, QLD: Queensland University Press.

Nakata, M. (2007). Disciplining the savages: savaging the disciplines, Canberra, ACT: Aboriginal Studies Press.

Scott, C.H. (2004). "Our feet are on the land, but our hands are in the sea": knowing and caring for marine territory at Erub, Torres Strait. In R. Davis (ed.) Woven histories, dancing lives: Torres Strait Islander identity, culture and history (pp. 259-270). Canberra, ACT: Aboriginal Studies Press.

Sharp, N. (1993). Stars of Tagai: the Torres Strait Islanders. Canberra, ACT: Aboriginal Studies Press.

Sharp, N. (1996). No ordinary judgment: Mabo, the Murray Islanders land case. Canberra, ACT: Aboriginal Studies Press.

Sharp, N. (2002). Saltwater people: the waves of memory. Sydney: Allen and Unwin. Spivak, G.C. (2003). Death of a discipline. New York: Columbia University Press. Spivak, G.C. (2012). An aesthetic education in the era of globalization. Cambridge, MA: Harvard University Press. 
Stratford, E., Baldacchino, G., McMahon, E., Farbotko, C. \& Harwood, A. (2011). Envisioning the archipelago. Island Studies Journal, 6(2), 113-130.

Suwa, J. (2007). The space of Shima, Shima, 1(1), 6-14.

Virilio, P. (1993). The third interval: a critical transition. In V. Andermatt-Conley (ed.) Rethinking Technologies (pp. 3-10). London: Minnesota University Press.

Walcott, D. (1990). Omeros. New York: Farrah, Straus \& Giroux. 